\title{
Cerebral palsy: association between nutritional status and occurrence of oropharyngeal dysphagia
}

\author{
Elenice França Dutra ${ }^{1}$ \\ https://orcid.org/0000-0002-5210-3736 \\ Aline Freitas Gomes ${ }^{1}$ \\ https://orcid.org/0000-0002-6356-1759 \\ Raquel Coube de Carvalho Yamamoto ${ }^{2}$ \\ https://orcid.org/0000-0002-2588-6616 \\ Franceliane Jobim Benedett ${ }^{1}$ \\ https://orcid.org/0000-0002-3334-3910 \\ Juliana Saibt Martins ${ }^{1}$ \\ https://orcid.org/0000-0003-4395-1036 \\ Camila Lehnhart Vargas ${ }^{1}$ \\ https://orcid.org/0000-0002-6509-9932
}

Universidade Franciscana (UFN), Santa Maria, RS, Brasil.

Universidade Federal do Rio Grande do Norte (UFRN), Natal, RN, Brasil.

Conflict of interests: Nonexistent

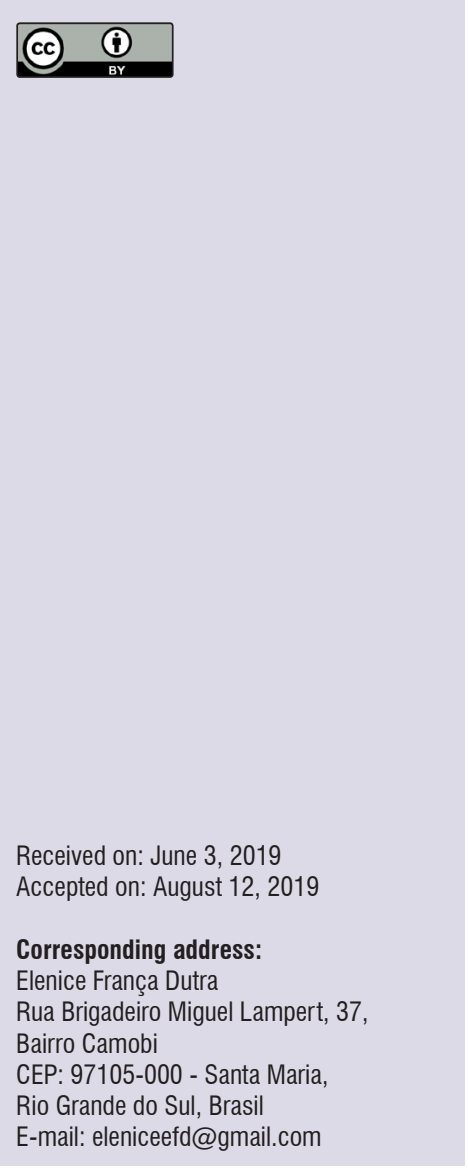

\section{ABSTRACT}

Objective: to verify the association between nutritional status and the occurrence of oropharyngeal dysphagia in individuals with cerebral palsy.

Methods: a cross-sectional, quantitative study with people aged between two and 20 years. Neuromotor impairment, occurrence and degree of dysphagia, anthropometry, food consumption, feeding route, diet fractionation and consistency were evaluated. Swallowing evaluation was performed by a skilled speech-language-hearing therapist, through the Clinical Evaluation Protocol of Pediatric Dysphagia (PAD-PED, Portuguese acronym). The statistical analysis was performed adopting $p<0.05 \%$.

Results: 40 subjects with a median of $8.7(5.45-14.5)$ years, $65 \%$ of whom were males. Concerning neuromotor impairment, $72.5 \%$ were classified at levels IV and V. The prevalence of dysphagia was $70 \%$, the feeding route being predominantly oral $(77.5 \%)$ with a normal diet consistency $(55 \%)$. In the growth curves, all of them were classified within an adequate height for their age. As for weight, body mass index and skinfolds, $82.5 \%, 85 \%$ and $62.5 \%$ were eutrophic, respectively. Statistically significant association was found between dysphagia and body mass index $(p=0.018)$. The mean daily caloric and proteic intake was $1427.29 \pm 338.62 \mathrm{kcal}$ and $56.86 \pm 17.57$ grams, respectively. Statistically significant association was found between the feeding route and the amount of protein ingested daily $(p=0.041)$.

Conclusion: most subjects presented oropharyngeal dysphagia and more severe motor impairment; they were fed orally with a normal diet consistency. It was observed that the greater the difficulty in swallowing, the greater the impairment of nutritional status.

Keywords: Cerebral Palsy; Swallowing Disorders; Nutritional Status; Food Consumption 


\section{INTRODUCTION}

Cerebral Palsy (CP) is a condition characterized by permanent movement, muscle tone and posture disorders, resulting from non-progressive lesions or malformations in the child's brain. In addition to sensorial and motor manifestation, it may be accompanied by cognitive, communicative, and behavioral disorders, as well as epilepsy and secondary musculoskeletal problems ${ }^{1}$.

The most common CP classifications may be according to bodily localization of neuromotor impairment: tetraplegia, hemiplegia and diplegia; and, type of alteration in muscle tone and posture: athetoid, ataxic, hypotonic, spastic and mixed. Another way of classifying is through the Gross Motor Function Classification System (GMFCS), a standardized system created to distinguish children and adolescents diagnosed with CP by levels of functional mobility².

$\mathrm{CP}$ etiology is multifactorial, so that risk factors may be divided in prenatal, perinatal or postnatal. In the first category, prematurity and infections stand out, such as rubella, toxoplasmosis and cytomegalovirus. Among the most prevalent perinatal and postnatal causes are anoxia and postnatal infections, as meningitis ${ }^{3,4}$, respectively. The prevalence is little studied in developing countries; however, in developed countries, it varies from 1.5 to $5.0 / 1,000$ live births. It's estimated that, in developing countries, the figure is of 7 for every 1,000 live births ${ }^{5}$. As for the epidemiologic profile, it seems to be more frequent among males ${ }^{6}$.

As a consequence of reduced brain oxygenation, these patients may suffer lesions in areas that control swallowing. Moreover, alterations in muscle coordination result in the inability of these people to maintain their posture and to perform normal movements. These associated factors characterize the occurrence of oropharyngeal dysphagia (OPD), which is estimated to affect from 19 to $99 \%$ of this population, being directly associated with the degree of motor impairment ${ }^{3,7}$.

One of the complications related to the occurrence of OPD is the worsening of nutritional status of these patients, who are considered at risk of malnutrition. Studies show that the more serious the level of motor impairment, the worse the dysphagia, and more frequent the occurrence of malnutrition ${ }^{8,9}$. Furthermore, due to the excessively long time taken to feed, and the need to change the consistency of meals because of dysphagia, the food intake of people with CP seems to be below the estimated daily need, frequently resulting in necessary enteral feeding. It can be observed that, the more seriously affected the motor function, the greater the association with feeding difficulties, which will consequently affect the adequate nutritional status. This is an important concern; therefore, the follow-up and monitoring of these patients is essential ${ }^{10}$.

In face of this situation, it's important to investigate the hypothesis that oropharyngeal dysphagia impairs food intake, and is related to the worsening of nutritional status of these patients, aiming at to provide better guidance regarding caregiving and the development of more efficient intervention strategies, in pursuit of improvement in this population's quality of life. Thus, the objective of this study was to verify the association between the nutritional status and the occurrence of oropharyngeal dysphagia in people with $\mathrm{CP}$.

\section{METHODS}

This paper derived from an academic Master's degree project in Health and Life Sciences at the Universidade Franciscana (UFN - Franciscan University), and it was approved by the Research Ethics Committee of this institution under Certificate of Presentation for Ethical Consideration protocol number 67483717.8.0000.5306.

This is a quantitative cross-sectional study developed in Santa Maria, state of Rio Grande do Sul, Brazil, at the Association of Parents and Friends of People with Intellectual Disability (APAE, its Portuguese acronym), and at the Practice Laboratory of the Franciscan University. The sample was selected by convenience, and the inclusion criteria were people previously diagnosed with $\mathrm{CP}$, of both genders, aged between two and 20 years, who attended the physiotherapy services of these institutions. These people were invited by the professional to participate in the research and, once accepted, referred for nutritional and speech-language-hearing assessment, at the same places. In all, 40 people met the inclusion criteria and accepted to participate in the research. The adults responsible for them signed the Informed Consent Form.

Initially, a physiotherapist evaluated the seriousness of neuromotor impairment through the GMFCS. This classification is based on movement initiated voluntarily, with emphasis on sitting, transferring and mobility. It's thus possible to classify the person with $\mathrm{CP}$ in five levels: I: walks without limitations; II: walks with limitations; III: walks with the support of a locomotion assisting device; IV: self-mobility with limitations, being 
able to use motorized assistive technology; V: transported by others on wheelchairs ${ }^{11}$.

The subsequent evaluation contemplated the anthropometric and dietary assessment, which were carried out by a nutrition student previously trained and supervised by a nutritionist. A questionnaire was also applied to identify the feeding route, and the diet fractionation and consistency. The feeding route was divided in three categories: oral (food being ingested exclusively through the mouth), enteral (fed exclusively via feeding tube), and mixed (concomitant oral and enteral). Fractionation corresponded to the number of meals had throughout the day. And diet consistency was classified in four categories: normal (without need of changing consistency);creamy (mashed, shredded or crushed food); liquid enteral; and, association between creamy and liquid enteral (for patients with both oral and enteral feeding).

In the anthropometric evaluation, weight and height were assessed whenever possible, in accordance with recommendations by the Nutrition and Food Surveillance System (SISVAN, its Portuguese acronym) $)^{12}$. The weight was assessed on a digital scale, brand Techline ${ }^{\circledR}$. In case the patient couldn't go up onto the scale, the one responsible for them was asked to go up onto it holding the patient in their arms, and then to weigh themselves alone; thus, with the difference between the two figures, the weight of the patient was found. The height was assessed on a pediatric stadiometer brand Pró Fisiomed ${ }^{\circledR}$.

In case the actual height couldn't be measured, the estimation was achieved by measuring the length of the knee, using Stevenson's formula developed specifically for children with CP up to 12 years old ${ }^{13}$. For the age group above 12 years, the height was equally estimated by the height of the knee, but with Chumlea formula, according to age and gender ${ }^{14}$.

With the figures for weight and height, the body mass index (BMI) was assessed. In the sequence, the data were placed in weight-for-age (W/A), heightfor-age $(H / A)$, and BMI-for-age $(B M I / A)$ curves, and so classified according to the GMFCS ${ }^{15}$. For the W/A, values below the percentile of 10 were considered thinness, values between the percentiles of 10 and 90 were considered eutrophy, and above the percentile of 90 were considered obesity. For H/A, patients with percentile below 10 were considered low height for the age, and above the percentile of 10 , adequate height for the age. And according to $\mathrm{BMI} / \mathrm{A}$ for $\mathrm{CP}$, thinness referred to values below the percentile of 10 , eutrophy between the percentiles of 10 and 90 , and obesity above the percentile of 90 .

To complement the anthropometric evaluation, the tricipital (TSF) and the subscapular (SSF) skinfolds were assessed. These measures were taken twice, using a calibrated clinical plicometer, brand CESCORF ${ }^{\circledR}$, and the average of the values found was considered for each skinfold. Afterwards, the classification was established, considering the sum of the skinfold values, so that above the percentile of 90 it was considered excessive adiposity, and below the percentile of 10 , low adiposity ${ }^{16}$.

The dietary assessment was carried out with the child's or adolescent's mother or caregiver, by means of the 24-hour record. The Dietwin software, version Dietwin Plus ${ }^{\circledR}$, was used to calculate the caloric and proteic values of the records. Then, the recommended daily caloric and proteic intake was calculated for each person, respectively by means of the EER (estimated energy requirement) and the RDA (recommended dietary allowance $)^{17}$.

Lastly, swallowing assessment was carried out by a skilled speech-language-hearing therapist through the Clinical Evaluation Protocol of Pediatric Dysphagia (PAD-PED, Portuguese acronym). Data were collected regarding identification, previous history, feeding history, and structural and functional clinical assessment. In addition to the findings from the general evaluation, this protocol presents the degree of pediatric dysphagia, which can be divided into four levels: 1- Normal swallowing; 2- Mild oropharyngeal dysphagia; 3- Moderate to severe oropharyngeal dysphagia; and, 4- Severe oropharyngeal dysphagia ${ }^{18}$.

The results from the analyses were described and expressed in average and standard deviation, or median and percentiles of 25 and 75 for the quantitative variables; and, for the categorical, absolute and relative frequencies were used. To associate motor function and dysphagia with the nutritional status, Fisher's exact test was applied. The association of energetic and proteic intake with BMI and feeding route was analyzed through the analysis of variance (ANOVA). The analysis of variance was complemented with Tukey's post hoc test. The level of significance adopted was of $5 \%$, and the analyses were carried out on the SPSS software (Statistical Package for the Social Sciences), version 18.0. 


\section{RESULTS}

A total of 40 patients were included in the analysis, with median of $8.7(5.45-14.5)$ years, $26(65 \%)$ of which were male. The average weight was of $25.82 \pm 11.69 \mathrm{~kg}$, Height of $120.96 \pm 20.6 \mathrm{~cm}$, and BMl of $16.8 \pm 3.65 \mathrm{~kg} / \mathrm{m}^{2}$.

In relation to neuromotor impairment, $72.5 \%$ of the subjects were classified in the levels IV and V of the GMFCS, which are considered the most severe and indicate dependence on other people's assistance for mobility. The prevalence of OPD was of $70 \%$, in which the majority of the sample presented mild degree. When associating BMI/A classification to skinfolds/ age according to GMFCS and swallowing, statistically significant association was found between swallowing classification and BMI/A. It was noted that, among those classified by the BMI as thinness, all presented moderate to severe OPD, and around $70 \%$ of those classified as eutrophy had some degree of dysphagia $(p=0.018)($ Table 1).

Table 1. Classification of body mass index and skinfolds for age in patients with cerebral palsy

\begin{tabular}{|c|c|c|c|c|c|c|c|c|c|}
\hline \multirow[b]{2}{*}{ Variable } & \multirow[b]{2}{*}{$\begin{array}{c}\text { Total } \\
n=44\end{array}$} & \multicolumn{4}{|c|}{ BMI/A } & \multicolumn{4}{|c|}{ Skinfold/A } \\
\hline & & $\begin{array}{c}\text { Thinness } \\
n=3\end{array}$ & $\begin{array}{c}\text { Eutrophy } \\
n=34\end{array}$ & $\begin{array}{c}\text { Obesity } \\
n=3\end{array}$ & $\mathbf{p}^{*}$ & $\begin{array}{c}\text { Low } \\
\text { adiposity } \\
n=10\end{array}$ & $\begin{array}{c}\text { Eutrophy } \\
n=25\end{array}$ & $\begin{array}{c}\text { Excessive } \\
\text { adiposity } \\
n=5\end{array}$ & $\mathbf{p}^{*}$ \\
\hline \multicolumn{10}{|l|}{ GMFCS } \\
\hline Level I & $8(20 \%)$ & 0 & $8(23.5 \%)$ & 0 & \multirow{5}{*}{0.065} & $2(20 \%)$ & $5(20 \%)$ & $1(20 \%)$ & \multirow{5}{*}{0.084} \\
\hline Level II & $1(2.5 \%)$ & 0 & 0 & $1(33.3 \%)$ & & 0 & $1(4 \%)$ & 0 & \\
\hline Level III & $2(5 \%)$ & 0 & $2(5.9 \%)$ & 0 & & 0 & $2(8 \%)$ & 0 & \\
\hline Level IV & $12(30 \%)$ & 0 & $10(29.4 \%)$ & $2(66.7 \%)$ & & $2(20 \%)$ & $9(36 \%)$ & $1(20 \%)$ & \\
\hline Level V & $17(42.5 \%)$ & $3(100 \%)$ & $14(41.2 \%)$ & 0 & & $6(60 \%)$ & $8(32 \%)$ & $3(60 \%)$ & \\
\hline \multicolumn{10}{|l|}{ Swallowing } \\
\hline Normal & $12(30 \%)$ & 0 & $10(29.4 \%)$ & $2(66.7 \%)$ & & $1(10 \%)$ & $10(40 \%)$ & $1(20 \%)$ & \multirow{4}{*}{0.059} \\
\hline Mild OPD & $14(35 \%)$ & 0 & $14(41.2 \%)$ & 0 & $0.018 * *$ & $6(60 \%)$ & $8(32 \%)$ & 0 & \\
\hline Moderate/severe OPD & $9(22.5 \%)$ & $3(100 \%)$ & $5(14.7 \%)$ & $1(33.3 \%)$ & & $3(30 \%)$ & $4(16 \%)$ & $2(40 \%)$ & \\
\hline Severe OPD & $5(12.5 \%)$ & 0 & $5(14.7 \%)$ & 0 & & 0 & $3(12 \%)$ & $2(40 \%)$ & \\
\hline
\end{tabular}

OPD: oropharyngeal dysphagia; GMFCS: Gross Motor Function Classification System; BMI/A: body mass index/age;

Values presented in $\mathrm{n}(\%)$; *Fisher's exact test; ${ }^{\star \star} \mathrm{p}<0.05$.

Concerning the growth curves, for $\mathrm{H} / \mathrm{A}$ all the patients were classified with adequate height for their age; for W/A, $5 \%$ of the subjects were found with thinness, $82.5 \%$ with eutrophy, and $12.5 \%$ with obesity; and in the BMI/A curve, there was $7.5 \%$ of cases with thinness, $85 \%$ with eutrophy, and $7.5 \%$ wit obesity. The average TSF was of $9.41 \pm 3.7 \mathrm{~mm}$, whereas the SSF was of $8.12 \pm 3.52 \mathrm{~mm}$. There were $25 \%$ classified with low adiposity, $62.5 \%$ with eutrophy, and $12.5 \%$ with excessive adiposity.

As for feeding route, 31 (77.5\%) people with CP had oral route, 6 (15\%), enteral route, and 3 (7.5\%) mixed route. For $22(55 \%)$ of them, the consistency of the diet offered was normal, 9 (22.5\%) had creamy diet, 6 (15\%) liquid enteral, and 3 (7.5\%) creamy and liquid enteral.
In the evaluation of food intake, the average fractionation was of $5.18 \pm 1.26$ meals/day. In relation to energetic ingestion, the daily average was found to be of $1427.29 \pm 338.62 \mathrm{kcal}$ and average EER of $1280.75 \pm 284.27 \mathrm{kcal}$. The group feeding exclusively through enteral route was the one who came closest to the EER. Table 2 shows the relation of caloric intake with $\mathrm{BMI} /$ age and feeding route.

The average proteic intake was of $56.86 \pm 17.57$ $\mathrm{g} /$ day and the average RDA, 30.18 $15.0 \mathrm{~g} /$ day. Statistically significant association was found between feeding route and the amount of protein ingested daily $(p=0.041)$. Table 3 presents the relation of proteic intake with BMI/age and feeding route. 
Table 2. Caloric intake and need associated with body mass index for age and feeding route, in patients with cerebral palsy

\begin{tabular}{|c|c|c|c|c|}
\hline Variable & TCI ingested (kcal) & $p$ value* & EER (kcal) & $p$ value $^{*}$ \\
\hline BMl/age & & \multirow{4}{*}{0.476} & & \multirow{4}{*}{0.030 ** } \\
\hline Thinness & $1507.89 \pm 275.32$ & & $1052.95 \pm 55.53^{a}$ & \\
\hline Eutrophy & $1401.53 \pm 339.01$ & & $1269.21 \pm 266.98^{\mathrm{a}}$ & \\
\hline Obesity & $1638.52 \pm 419.41$ & & $1639.33 \pm 351.61^{b}$ & \\
\hline Feeding rout & & & & \multirow{4}{*}{0.180} \\
\hline Oral & $1463.19 \pm 324.76$ & \multirow{3}{*}{0.356} & $1324.16 \pm 336$ & \\
\hline Enteral & $1243.41 \pm 367.28$ & & $1164 \pm 175.85$ & \\
\hline Mixed & $1424.01 \pm 441.89$ & & $1065.67 \pm 75.62$ & \\
\hline
\end{tabular}

EER: estimated energy requirement; BMI: body mass index; TCl: total caloric intake;

Values presented in average \pm standard deviation; *ANOVA post hoc Tukey (differences between superscript letters); ${ }^{*} \mathrm{p}<0.05$.

Table 3. Proteic intake and recommendation associated with body mass index for age and feeding route, in patients with cerebral palsy

\begin{tabular}{ccccc}
\hline Variable & PTN ingested $(\mathbf{g} /$ day) & p value & RDA $(\mathbf{g} /$ day $)$ & p value $^{*}$ \\
\hline BMl/age & & & & \\
Thinness & $51.98 \pm 14.78$ & 0.533 & $29.94 \pm 15.24$ & 0.120 \\
Eutrophy & $56.37 \pm 17.19$ & & $44 \pm 9.16$ & \\
Obesity & $67.25 \pm 26.93$ & & & \\
Feeding route & & & $32.94 \pm 14.78$ & \\
Oral & $60.56 \pm 16.62^{\mathrm{a}}$ & $0.041^{\star *}$ & $23.50 \pm 14.16$ & 0.067 \\
Enteral & $43.24 \pm 17.13^{\mathrm{b}}$ & & $15 \pm 3.46$ & \\
Mixed & $45.8 \pm 13.82^{\mathrm{b}}$ & & & \\
\hline
\end{tabular}

BMI: body mass index; PTN: protein; RDA: recommended dietary allowance;

Values presented in average \pm standard deviation; *ANOVA post hoc Tukey (difference between superscript letters); ${ }^{*} \mathrm{p}<0.05$.

\section{DISCUSSION}

This study found CP to have $65 \%$ of prevalence in males, as well as in other researches. A paper developed in the United States, which assessed 24,920 patients, found $57 \%$ of prevalence in men ${ }^{15}$. In Brazil, a research involving 236 children with CP cared for in a hospital in São Paulo also found a predominance of males $\left(60.2 \%\right.$ of the cases) ${ }^{19}$. Indeed, CP seems to be more frequent in men, and, even though the causes are not clearly known, one of the accepted hypotheses is that the sexual hormones, especially the estrogen, act as a protective factor on the female's brain ${ }^{5}$.

regarding swallowing, $70 \%$ of the sample in this paper presented some degree of OPD, in agreement with others which also found high indexes. In a research involving 130 children with CP, 93.8\% presented deficiency in the oral phase while eating and drinking, or when controlling the saliva ${ }^{20}$. Another study, when carrying out the swallowing clinical and functional analysis in 67 children with spastic $\mathrm{CP}$, showed that $61 \%$ of them presented dysphagia symptoms ${ }^{21}$.

The general nutritional status of the population in this paper obtained inadequacy indexes lower than $20 \%$ for $\mathrm{W} / \mathrm{A}, \mathrm{H} / \mathrm{A}$ and $\mathrm{BMI} / \mathrm{A}$, disagreeing with researches that had found high indexes of malnutrition $^{9}$. The difference in results may be explained by the evaluation method used, since this study employed growth curves specific for $\mathrm{CP}$, whereas others make use of parameters intended for the general population, which don't seem to be the most adequate, as they don't take into account the level of motor impairment. In a cross-sectional study with 187 people with CP that assessed anthropometric data in curves specific for $\mathrm{CP}$ and in curves normally used in pediatrics, weight results below the percentile of 10 occurred in $10 \%$ of the sample, considering the CP scale, against $51 \%$ in the reference from the Center of Disease Control. The authors concluded that the references normally used in pediatrics tend to overestimate malnutrition in these 
patients, and their agreement with references specific for $\mathrm{CP}$ is low ${ }^{22}$. In this regard, it's emphasized that, even when properly nourished, children with $\mathrm{CP}$ are smaller than children from the general population, possibly due to physical inactivity, mechanical forces exerted on the bones, articulations and muscles, endocrinal factors, high prevalence of prematurity, and low birth weight. These factors seem to act synergistically to affect growth in each of its dimensions, including diminished linear growth, weight gain, and alterations in body composition, such as reduced muscle mass, fat mass, and bone density. Achieving anthropometric indexes of weight and height established for the general population mustn't be the goal when dealing with people with $\mathrm{CP}$ and their health and growth ${ }^{11}$.

The results demonstrated that, regardless of the classification by the BMI, the subjects presented OPD in the different levels. Depending on the degree of motor and/or neurologic impairment presented by the person, the phases of oral, pharyngeal and esophageal swallowing may suffer interferences ${ }^{23}$. These conditions usually require more time for feeding, and the use of appropriate utensils is made necessary, as well as an adequate consistency preparation to ensure the safety of the protection of the lower respiratory tract. The impairment of nutritional aspects is many times closely connected to oral motor difficulties presented by the patient; the excessive amount of time used in feeding and the effort necessary to perform such task may be risk factors for the development of malnutrition, once the caloric expenditure may not be sufficient for an effective nutritional ingestion ${ }^{24}$.

A research involving 230 children with moderate to severe CP (GMFCS III a V), performing anthropometric assessment, concluded that in these children feeding disorders are common and are associated with the impaired nutritional status. Even patients with moderate disorder require chopped and mashed food, which may pose a risk for the maintenance of the adequate nutritional status ${ }^{7}$. In Brazil, a study involving 114 children with $\mathrm{CP}$, assessing their weight, height, BMI, arm muscle area, and arm fat area, found frequent malnutrition. The children with tetraplegic CP presented the most impaired anthropometric indicators: weight and BMI, with $72.4 \%$ and $73.1 \%$, with Z-score $\leq-2$ respectively. The authors concluded that one of the factors that significantly influenced the nutritional status of the sample was the difficulty to swallow ${ }^{25}$.

As for food intake, this paper hasn't found any statistically significant association between nutritional status and energetic ingestion; in this regard, some factors may have brought limitations. Indeed, it's difficult to assess the energetic need of children with neurologic difficulties, as there are no specific recommendations appropriate for this kind of patient. The DRIs (Dietary Reference Intake) tend to overestimate their energetic need, for this population seems to have basal metabolic rate (BMR) lower than healthy children in the same age group, due to their delayed growth and low level of physical activity ${ }^{26}$. A research used the method of electrical bioimpedance to calculate and compare the BMR between 40 children with $\mathrm{CP}$ and a control group with 40 healthy children, and obtained respective average of $689.4 \pm 62.2 \mathrm{kcal}$ and $735.8 \pm 51.7$ $\mathrm{kcal}^{27}$. Furthermore, in the 24-hour record, in spite of being one of the most used methods for evaluating food intake and having the advantage of being easily applied and of low cost, there's the possibility of error, especially because it doesn't consider the daily intra- and interpersonal variations, and it depends on the interviewee's memory, which makes it difficult to quantify the nutrients ${ }^{8}$. For this reason, studies that use such food record don't always present similar results. In this study, energetic and proteic intake was above the recommended for the analyzed variables; this result is similar to that found in another paper that assessed 47 patients with CP aged from two to 12 years, and concluded that there was a tendency to overfeed these children ${ }^{28}$. Another research found caloric intake in average $25 \%$ below the recommended by the RDA, whereas the proteic intake was twice the recommended for those assessed. It should be highlighted that a hyperproteic diet may work as a protective factor against malnutrition, as long as the energetic needs are met $^{8}$.

It's also important to highlight the results found from the association between intake and feeding route. Both for energetic and proteic intake, the patients fed exclusively via enteral tubes were the ones that came closest to the recommendation; concerning this, there was found statistically significant association between proteic intake and feeding route $(p=0.041)$. The benefits of enteral feeding for people with $\mathrm{CP}$ have already been studied before. A prospective cohort followed up 57 children that were assessed before the gastrostomy tube was inserted, and then six and 12 months afterwards. The results showed substantial improvement in weight, height and fat mass of the patients. Complications were rare, and no evidence of increase in respiratory problems was found. Moreover, 
most of the parents reported an improvement in their children's health, as well as a significant decrease in the time spent in feeding ${ }^{29}$.

Another research evaluated qualitatively and quantitatively the profile of patients with CP regarding the use of gastrostomy, and verified the emotional effect the tube-using procedure had on the caregivers. The results pointed to the difficulty in swallowing as unanimous motive for the gastrostomy to be indicated. as for the caregivers, it showed that they were initially afraid of the unknown, and were thus resistant to accept the surgical procedure. They found it also difficult to accept that the child would no longer feed exclusively through their mouth. However, after the surgery, a great number of the caregivers reported such benefits as weight gain, decrease in respiratory problems, and less hospitalizations. The authors highlighted the importance of demystifying the use of gastrostomy as a permanent discontinuation of oral feeding, since it's possible to gradually reintroduce it with the assistance of a speechlanguage-hearing therapist, once the caloric and respiratory needs of the child are ensured ${ }^{30}$.

People with cerebral palsy need to be early intervened in the aspects involving nutritional status and the occurrence of dysphagia. Developing an interdisciplinary therapeutic plan for assessment and follow-up is essential for the patient's quality of life, as it broadly reduces complications that might otherwise interfere in their clinical condition.

\section{CONCLUSION}

This study had most of its sample classified in the most severe level of neuromotor impairment, and with a high frequency of dysphagia. Low indexes of thinness and obesity were found, though it was still possible to establish a direct association between $\mathrm{BMI}$ and swallowing. As for food intake, most participants were fed orally and had a diet with a normal consistency; no association with nutritional status was found, although there was a relationship between proteic intake and feeding route.

In face of these factors, it was possible to verify a relationship between the occurrence of dysphagia and the nutritional status of the patients in this study, as the greater the difficulty in swallowing, the greater the nutritional status impairment.

Lastly, further studies are necessary for the establishment of more precise parameters to evaluate the caloric and proteic intake and need of people with $\mathrm{CP}$, and associate them with the presence of alterations in oral motor functions.

\section{ACKNOWLEDGEMENT}

Special thanks to the Association of Parents and Friends of People with Intellectual Disability (APAE) of Santa Maria, RS, Brazil, and to the Franciscan University (UFN), for offering their facilities for the assessment of the patients in this study.

\section{REFERENCES}

1. Rosenbaum P, Paneth N, Leviton A, Goldstein M, Bax M. A report: the definition and classification of cerebral palsy April 2006. Dev Med ChildNeurol. Supplement. 2007;109(109):8-14.

2. Palisano $R$, Rosenbaum $P$, Walter $S$, Russell $D$, Wood E, Galuppi B. Development and reliability of a system to classify gross motor function in children with cerebral palsy. Dev Med Child Neurol. 1997;39(4):214-23.

3. Piovesana AMSG, Val Filho JAC, Lima CLA, Fonseca MS, Mürer AP. Encefalopatia crônica: paralisia cerebral. In: Fonseca LF, Pianetti G, Xavier CC (orgs). Compêndio de neurologia infantil. $2^{\underline{a}}$ ed. Rio de Janeiro: Medsi, 2002. p. 826-37.

4. Vianna CIO, Suzuki HS. Paralisia cerebral: análise dos padrões de deglutição antes e após intervenção fonoaudiológica. Rev. CEFAC. 2011;13(5):790-800.

5. Zanini G, Cemin NF, Peralles SN. Paralisia cerebral: causas e prevalências. Rev. Fisioter Mov. 2009;22(3):375-81.

6. Johnston MV, Hagberg $H$. Sex and the pathogenesis of cerebral palsy. Dev Med Child Neurol. 2007;49(1):74-8.

7. Erasmus CE, Hulst KV, Rotteveel JJ, Willemsen MAAP, Jongerius PH. Clinical practice: swallowing problems in cerebral palsy. Eur $\mathrm{J}$ Pediatr. 2012;171(3):409-14.

8. Fung EB, Fang LS, Stallings VA, Conaway M, Liptak G, Henderson RC et al. Feeding dysfunction is associated with poor and health status in children with cerebral palsy. J Am Diet Assoc. 2002;102(3):361-73.

9. Linhares FMP. Avaliação do estado nutricional de crianças com disfagia por paralisia cerebral [dissertação]. Santa Maria (RS): Universidade Federal de Santa Maria; 2004. 
10. Stevenson RD. Beyond growth: gastrostomy feeding in children with cerebral palsy. Dev Med Child Neurol. 2005;47(2):76-76.

11. Brasil. Ministério da Saúde. Secretaria de Atenção à Saúde. Departamento de Ações Programáticas Estratégicas. Diretrizes de atenção à pessoa com paralisia cerebral. Brasília: Ministério da Saúde; 2014.

12. Brasil. Ministério da Saúde. Secretaria de Atenção à Saúde. Departamento de Atenção Básica. Orientações para a coleta e análise de dados antropométricos em serviços de saúde: Norma Técnica do Sistema de Vigilância Alimentar e Nutricional - SISVAN. Brasília: Ministério da Saúde; 2011.

13. Stevenson RD. Use of segmental measures to estimate stature in children with cerebral palsy. Arch Pediatr Adolesc Med. 1995;149(6):658-62.

14. Chumlea WC, Guo SS, Steinbaugh ML. Prediction of stature from knee height for black and white adults and children with application to mobilityimpaired or handicapped persons. J Am Diet Assoc. 1994;94(12):1385-8.

15. Day SM, Strauss DJ, Vachon PJ, Rosenbloom L, Shavelle RM, Wu YW. Growth patterns in a population of children and adolescents with cerebral palsy. Dev. Med. Child. Neurol. 2007;49(3):167-71.

16. Frisancho AR. Anthropometric standards for the assessment of growth and nutritional status. Ann Arbor: University of Michigan Press; 1990.

17. Institute of Medicine. Food and Nutrition Board. Dietary reference intakes for energy, carbohydrate, fiber, fat, fatty acids, cholesterol, protein and amino acids. Washington, DC: National Academies Press; 2001.

18. Almeida FCF, Bühler KEB, Limongi SCO. Protocolo de avaliação clínica da disfagia pediátrica (PAD-PED). 1 ed. Barueri: Pró-Fono; 2014.

19. Caraviello EZ, Cassefo V, Chamlian TR. Estudo epidemiológico dos pacientes com paralisia cerebral atendidos no Lar Escola São Francisco. Med. Reabil. 2006;25(3):63-7.

20. Benfer KA, Weir KA, Bell KL, Ware RS, Davies PSW, Boyd RN. Oropharyngeal dysphagia in preschool children with cerebral palsy: oral phase impairments. Res. Dev. Disabil. 2014;35(12):3469-81.

21. Otapowicz D, Sobaniec W, Okurowska-Zawada B, Artemovicz B, Sendrowski K, Kulak $W$ et al. Dysphagia in children with infantile cerebral palsy. Adv Med Sci. 2010;55(2):222-7.
22. Araújo LA, Silva LR. Anthropometric assessment of patients with cerebral palsy: which curves are more appropriate? J Pediatr. 2013;89(3):307-14.

23. Benfer KA, Weir KA, Bell KL, Ware RS, Davies PSW, Boyd RN. Longitudinal study of oropharyngeal dysphagia in preschool children with cerebral palsy. Arch Phys Med Rehab. 2016;97(4):522-60.

24. Brooks J, Day S, Shavelle R, Strauss D. Low weight, mobidity, and mortality in children with cerebral palsy: new clinical growth charts. Pediatrics. 2011;128(2):299-307.

25. Caram ALA, Morcillo AM, Pinto EAL. Estado nutricional de crianças com paralisia cerebral. Rev Nutr. 2010;23(2):211-9.

26. Romano C, Wynckel MV, Hulst J, Broekaert I, Bronsky J, Dall'Oglio L et al. ESPGHAN guidelines for the evaluation and treatment of gastrointestinal and nutricional complications in children with neurological impairment. JPNG. 2017;65(2):242-64.

27. Tomoum HY, Badawy NB, Hassan NE, Alian KM. Anthropometry and body composition analysis in children with cerebral palsy. Clin. Nutr. 2010;29(4):477-81.

28. Mota MA. Concordância entre métodos de avaliação nutricional em crianças e adolescentes com paralisia cerebral [dissertação]. Porto Alegre (RS): Universidade Federal do Rio Grande do Sul; 2010.

29. Sullivan PB, Juszczak E, Bachlet AME, Lambert B, Vernon-Roberts A, Grant HW et al. Gastrostomy tube feeding in children with cerebral palsy: a prospective, longitudinal study. Dev. Med. Child. Neurol. 2005;47(2):77-85.

30. Susin FP, Bortolini V, Sukiennik R, Mancopes R, Barbosa LR. Perfil de pacientes com paralisia cerebral em uso de gastrostomia e efeito nos cuidadores. Rev. CEFAC. 2012;14(5):933-42. 